\title{
Can the Tana Mangabey Survive?
}

\section{Katherine Homewood}

Found in only one small area in north-east Kenya, the Tana mangabey is both seriously depleted and highly endangered. Numbers are estimated at under 1500. The author, who spent two years on a field study in the Tana River area, shows how the combination of increased pressure from the growing human population and the long-term effects of new hydroelectric and irrigation schemes will affect especially the food supply of this monkey, which has adapted itself to a complicated river regime that may now be destroyed.

The Tana River mangabey, Cercocebus galeritus galeritus, a large slender Cercopithecine monkey with fawn-grey fur and a semi-prehensile tail, is found only in small patches of gallery forest on the Tana River in north-eastern Kenya. This is a relict population of a once widely distributed species; its closest relatives, the subspecies $C$. g. agilis and C. g. chrysogaster, now inhabit the gallery forests of the Congo Basin some $1500 \mathrm{~km}$. to the west. Until recently little was known about $C$. galeritus in general and the rare and isolated C. g. galeritus in particular. In July 1972, Dr Colin Groves led an expedition to the Tana to make a general survey of the mangabey's range and habitat. The present study of the Tana mangabey's socioecology has been in progress since October 1972.

\section{Habitat}

The Tana is Kenya's longest river. Its course from mountain ravine through meandering floodplain to swampy estuary runs mainly through arid land, apart from a $60-\mathrm{km}$. stretch of the floodplain that supports patches of forest and woodland. Here it builds up sandy levees by continuous deposition, and, when the seasonal rains in the catchment area are sufficiently heavy, overflows to flood the 5-mile wide plain. During such floods the river tends to change its course, the swollen waters burst through weakened banks and narrowed meander loops, creating new channels and leaving cut-off levees and ox-bow lakes. The forests, which for reasons of soil type, drainage and groundwater supply are concentrated on raised riverside levees, are thus in a continuously changing system. The vegetation in fact comprises a dynamic mosaic consisting of areas newly exposed to colonisation, young forests of colonisers with limited diversity, more mature forests attaining some degree of vegetational diversity and stability, and dying/degrading forests which have been cut off at any of these stages by a change in the river's course. These little patches of true forest, each no more than a few hectares, are linked by stretches of edaphic deciduous woodland, bush and grass on soils that are poorer, less permeable, more saline and more subject to flooding. The vegetation pattern is complicated by felling, clearing and burning for agriculture and pasture, and to a lesser extent by the effects of elephant damage.

A general survey of the range, status and habitat of the two rare endemic Tana monkeys, the mangabey and the red colobus Colobus badius rufomitratus by Colin P. Groves, Peter Andrews and Jennifer F. M. Horne, was published in the last Oryx, November 1974. 


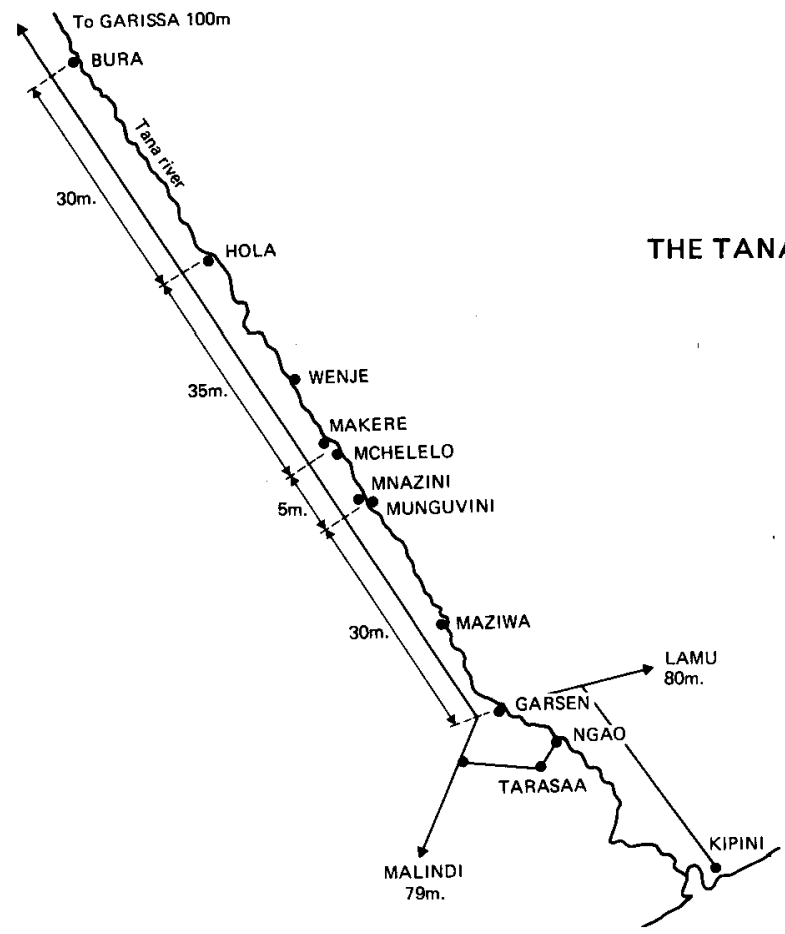

\section{Fauna}

The seven primate species living in the Tana forest and woodlands are the rare mangabey C.g.galeritus and red colobus Colobus badius rufomitratus*, Sykes's and vervet monkeys Cercopithecus mitis and C.aethiops, yellow baboon Papio cynocephalus and two bushbaby species. Red duikers, waterbuck, bushbuck, buffalo and leopard are found in the woods throughout the year. In the surrounding areas of bush and grassland are ostriches, wild dog, jackals, hyena, lion, warthog, Peters's gazelle, impala, gerenuk, eland, oryx, zebra, giraffe, and rhino, with crocodiles, hippos and a variety of water birds in the river and lakes. Large numbers of elephants invade the area in the dry season.

\section{Human Population}

The river banks are inhabited by the Pokomo tribe, river people who live by fishing and shifting cultivation. They are not hunters, but their expanding population and slash-and-burn cultivation are progressively compressing the forests - the familiar conflict between man and wildlife for space and natural resources. As well as clearing forest areas for agriculture, the Pokomo fell trees to make their houses and dugout canoes. For house-building they use small saplings of all tree species, generally those that are common and easily replaced, but canoes are made from large trees which may be 100 years old or more. These are important food sources and structural elements for primates

* At present being studied by Clive Marsh of Bristol University on a New York Zoological Society grant. See Note on page 3. 
and other animals, and are not rapidly replaceable; owing to the shifting water supply replacement saplings may be unable to establish themselves. As the canoes are sometimes abandoned half-made, or, if completed, may last for only a year (eg Ficus sp.) to 4-5 years (Diospyros sp.), the recruitment rate of sizeable trees is inadequate for the needs of man and wildlife.

The floodplain is also inhabited by pastoral tribes, chiefly the Orma, who regularly burn off grass and bush to improve the grazing. This has the effect of maintaining fire climax pastures where otherwise bush or regenerating woodland might grow; the fires may also destroy the edges of existing woodland and forest.

\section{Development and Conservation}

Until fairly recently the cropping of large trees, the slash-and-burn shifting cultivation of the Pokomo, and the fire climax pastures of the semi-nomadic Orma were consistent with the cyclic mosaic pattern of the Tana floodplain ecosystem. The Pokomo villages and clearings grew, shifted and died as the river changed its course; cleared areas were always planted with a few mango trees and palms which would later form the nuclei for regenerating forest. But the rapid population increase over the last fifty years has accelerated habitat destruction without allowing comparable regeneration. In addition hydroelectric dams under construction upstream and a planned 40,000-acre irrigation scheme extending from Bura downstream, potentially as far as Wenje, the northern distribution limit of the Tana mangabeys and colobus, will drastically alter the present river regime. At worst these could

1. Eliminate flooding.

2. Cut down the present highly variable flow to a steady flow of around half the present average.

3. Eliminate most of the silt content.

4. Pour large quantities of chemical fertiliser and pesticide (specifically DDT) into the river.

Apart from the complex results to be expected from chemical pollution, some other more obvious effects on the downstream ecosystem may be predicted:

1. With the loss of flooding, cutting power and silt content, the river will be stabilised in its present course.

2. The decrease in flow will affect the ground water table dependent on seepage from the river. Trees dependent on this water will fail to reproduce and/or die, leading to an overall decrease in total area of woodland and forest.

3. The long-term effect will be a change from what has until now been a cyclic ecosystem to a stable one. Forests surviving along the stabilised river course will eventually reach stable maturity, hitherto precluded by the dynamic cycle of colonisation and death as the river shifted. This means a change of species composition and abundance. A cyclic ecosystem, in which each unit of the mosaic develops along the same predictable course until the inherent instability of the system - here represented by the river - causes it to break down and start anew, combines features of both young and mature systems. Similarly the species of such an ecosystem possess both 'pioneer' and 'specialist' characteristics (see Table 1). In terms of the plant community, permitting such a system to achieve maturity is ultimately equivalent to condemning the pioneer species. These are the species with the most rapid and prolific turnover of shoots, fruits and seeds, which are major diet items for the primates and other forest animals. Thus the animals will be directly affected, and the present study indicates that the species to suffer most will be the Tana mangabey. 


\section{Table 1 Classification of Plant Species Types adapted from Margaleff}

\begin{tabular}{|c|c|c|c|}
\hline Life snan & $\begin{array}{l}\text { Pioneer } \\
\text { short }\end{array}$ & $\begin{array}{l}\text { Specialist } \\
\text { long }\end{array}$ & Cyclic-Adapted \\
\hline Reproduction & prolific & low & \\
\hline Dispersal & effective & poor & effective \\
\hline Tolerance & wide & narrow & $\begin{array}{l}\text { wide, comprising } \\
\text { predictable limits } \\
\text { of the cycle }\end{array}$ \\
\hline $\begin{array}{l}\text { Integration, } \\
\text { behavioural/ }\end{array}$ & & & \\
\hline biochemical & low & high & as above \\
\hline Genetic stability & low & high & high \\
\hline Selection criterion & $\begin{array}{l}\text { opportunity } \\
\text { (directional) }\end{array}$ & $\begin{array}{l}\text { efficiency } \\
\text { (stabilising) }\end{array}$ & $\begin{array}{l}\text { versatility within } \\
\text { limits of the cycle }\end{array}$ \\
\hline
\end{tabular}

\section{Primate study}

\section{Methodology}

1. Physical environment: a. Climatic records (thermohygrograph and rain gauge)

2. Vegetation:
b. River flow
c. Soil and geomorphology $\}$ scheme records
a. Pairs of $5 \mathrm{~m}^{2}$ quadrats at $50 \mathrm{~m}$ intervals throughout the intensive study area (c. 30ha.) are used for recording species, numbers of individuals, canopy heights, cover classes and cause and degree of damage.
b. Monthly phenology of 10 major food species (10 marked individuals of each); additional notes on other species.
c. Monthly assessment of leaf litter (fruit, seed and invertebrate content) for 5 pairs of $50 \mathrm{~cm}^{2}$ quadrats.
d. Visits to all forest patches to determine species composition, abundance, damage, etc.

3. Primates:

a. Monthly $2 \mathrm{~km}$. census walk through three habitat types.

b. All-day (0630-1800) follows with systematic data samples for

i) one semi-habituated group in prime evergreen forest;

ii) one habituated group in sub-optimal deciduous woodland.

c. Trapping and blood-sampling for chromosome and protein electrophoresis studies.

Systematic data-collection as outlined yields large quantities of data requiring computer analysis (to be conducted after completion of the field work). It is thus not possible to give figures as yet: however, the main trends are already clear.

\section{Preliminary Results}

The mangabeys live in troops of 13-36 individuals with at least one and usually more adult males. Excess males occur as peripheral, solitary individuals. The size and range of any one troop are related to the extent and vegetation type of the forest or woodland it inhabits. The density thus varies from about 3 
animals per hectare, with a range of as little as 15 hectares in optimal diverse evergreen forest, to less than 1 per 2 hectares on poor, low-diversity deciduous woodland, where they may range over 50-100ha. in the course of the year. These figures, when combined with the calculated total area of forest and woodland inhabited (c. $15 \mathrm{~km} .{ }^{2}$ as assessed from available $1: 100,000$ and $1: 50,000$ maps), give a population estimate of between 1000 and 1500 surviving Tana mangabeys which is rather less than the tentative figure suggested by Groves et al.

The mangabeys are opportunistic feeders, eating mainly fruits, seeds and insects. Over 50 food species and well over 100 separate food items have been recorded. They are semiterrestrial, equally at home $30 \mathrm{~m}$. up in the trees (though not so agile as the mainly aboreal C. mitis) or down on the ground, where they spend much of their day foraging in the leaf litter. They travel along the ground between adjacent forest patches, but not over such long distances nor through such open territory as the baboons.

The social behaviour of the mangabeys shows certain characteristic features. During the dry season when the food supply is limiting, the social groups maintain discrete territories with minimal overlap, the adult males of each group giving long-range spacing vocalisations and territorial displays at fixed boundaries and sometimes joining in active combat with trespassing alien group leaders. During the rains, when food is abundant, these territorial boundaries appear to break down: groups range more widely, with considerable overlap, and are tolerant of one another, meeting and showing some intermingling. At this time temporary associations of 40-50 mangabeys may be found, sometimes around a concentrated food source, sometimes unrelated to any such obvious environmental factor.

The individual social groups usually have two or more adult males. There is evidence that this is not simply a result of an 'age-graded' structure, and that if a group loses one of its adult males another will be recruited from peripheral solitary males to maintain the typical ratio. In the habituated study group, which increased from 13 to 16 individuals during 1973, the adult male: female ratio has changed from $1: 2.5$ to $1: 2$. The ratio for the other, larger study groups cannot yet be determined, but each appears to have at least 3 fully adult and 2 young adult males for a total of 25-30 individuals.

Within the group, relations seem to be dictated primarily by matrilineal ties. For the first two months after birth an infant is jealously guarded by its mother; the third month it socialises more with its peers and other members of the group, but still associates chiefly with its mother. With maturing females this is a lasting attachment; developing males gradually become more independent, spending more and more time on the periphery or entirely away from the group. Such 'solitaries' may eventually join other groups with a 'vacancy' for an adult male.

\section{Discussion}

Cercocebus galeritus is an exception to the statement that 'gallery forests have less distinctive primates . . . mainly the inhabitants of wet forest or woodland' (Jolly, 1972). From their geographical distribution, and particularly their conspicuous absence from all non-riverine but otherwise apparently suitable linking forests, the three races of $C$. galeritus seem to be specifically dependent on seasonally flooding riverine forest. A concurrent study of C. galeritus agilis 
in West Africa (Quris, 1973) shows that the morphology, ecology and social behaviour of this race seem closely similar to those of the Tana mangabeys. Just as for plant species, the animal species of a cyclic ecosystem might be expected to show a combination of pioneer and specialist features. While neither so hardy as a simple generalist nor so efficient as a specialist, their intermediate versatility would enable both to survive the difficult stages of the cycle and to exploit the more favourable. It seems that, compared to the other primates of the area, the mang abey is just such a species.

\section{Dispersal}

a. Semi-terrestriality enables the Tana mangabeys to visit, exploit and/or colonise distant, isolated forest stands hardly accessible to a predominantly arboreal monkey.

b. The behavioural tendency to range more widely when food is not limiting is equivalent to exploration. In a society of long-lived, intelligent primates it may be the basis for future colonisation of newly generating forest stands.

\section{Wide tolerance}

The capacity to eat virtually any plant species available as well as any insect, millipede, snail, etc., that may turn up is of undoubted value in a fluctuating system.

\section{Behavioural integration}

a. Flexible social grouping varying according to seasonal food conditions permits maximal efficiency of foraging, exploratory ranging and perhaps even exogamy. Similar seasonal variation in social groupings has been found in the hunter-gatherer bushmen (Lee, 1968) where they serve a similar adaptive function.

b. Semi-terrestrial behaviour enables the mangabeys to exploit arboreal food sources and structural elements barely accessible to the mainly terrestrial baboons.

\section{Genetic stability}

Superficial evidence for genetic stability is provided by the close morphological, ecological and behavioural similarity of the widely separated, longisolated populations of the Tana River and the Congo Basin. It is hoped that the results of chromosome and protein studies will bear this out.

Thus evidence from distribution, ecology and behaviour suggests that $C$. galeritus, intermediate between and in competition with other more specialised primate species, has survived only in the cyclic but predictable ecosystems afforded by flooding and shifting riverine forest mosaic, where its versatility represents a preadaptive advantage. As the Tana River is being harnessed and the former floodplain system stabilised, this theory will be put to the test. In the more severe competition resulting from a reduction of the habitat, and with the stabilisation of the forests, the Tana mangabeys are unlikely, in the long term, to survive.

Any conservation scheme put forward must take account of national interest as well as the interests of the local people and the wildlife. The initial aim is to establish a number of viable and if possible lucrative schemes in the area which would justify or at least compensate for any inconvenience caused 
by a reserve. The aim of the reserve would be at least short-term conservation even if, in the case of the mangabeys, replacement is in the long run inevitable.

\section{Nature reserve}

The area gazetted for protection includes all forest patches between Makere and Mnazini on the west bank, and between Wenje and Kitere on the east bank, a distance of 7-8 miles. Groves et al. have already discussed in the last Oryx a number of measures needed to ensure co-operation from the local inhabitants, the Pokomo villagers. Clive Marsh in conjunction with the Kenya Game Department planned and is now organising this nature reserve.

To provide some form of revenue from the protected area, it is proposed that a tented camp for tourists be established at Mchelelo, and later a second, similar one at Kipini, on the coast, which would have the added attractions of bathing, deep sea-fishing, etc. Such a camp, run purely for private enterprise, already exists at Maziwa. Visitors on excursions from Malindi or on the Garissa-Lamu-Malindi circuit would be offered excellent game viewing, boat trips on the river, rare-monkey spotting walks in the forest, traditional dances at nearby villages, etc. This would provide some employment for local Pokomo, and a fixed proportion of the charge for each guest would be paid over to the local county council. Additional revenue, as at present, would continue to come from licensed hunting of game animals. The Pokomo would be further compensated by preferential access to the irrigation scheme lands, and if possible artificial canoes (fibreglass) could be made available at low cost; being more durable they could rapidly replace the dugouts.

\section{Potential Commercial Schemes}

1. The Pokomo are traditionally fishers, and a small freezing plant for tilapia exists at Tarasaa, 12 miles from Garsen. Production could be increased using more intensive methods.

2. Full implementation of the Bura scheme may preclude any other irrigation schemes downstream; however, the present rather opportunistic cultivation of apple mangoes, coconuts etc. could be organised to give a higher yield, and new delicacy crops (e.g. melons) could be introduced, particularly in the areas downstream from Garsen.

\section{Acknowledgments}

Financial aid was provided for the study by: The New York Zoological Society, the Royal Society Leverhulme Overseas Studentship, the East African Wildlife Society, the Boise Fund, London University Central Research Fund and the Horniman Trust.

\section{References}

ARERE, A. Kenya's Power Plans. Kenya Economic Survey K 31. African Development December 1974.

GROVES, COLIN P., ANDREWS, P., and HORNE, J. F. M. 1974. Tana River Colobus and Monkey. Oryx XII, 5.

HOMEWOOD, K. Monkey on a River Bank. Natural History, New York, January 1975. JOLLY, A. 1972. Evolution of Primate Behaviour. Macmillan.

LEE, R. B. 1968. Man the Hunter. Aldine, N.Y.

QURIS, R. Emissions sonores servant au maintien du groups social de Cercocebus galeritus agilis. Biolog. Gabon'II 1973.

This article was received in March 1974. 